\title{
A MULTISSERIAÇÃO FRENTE À PROFISSIONALIDADE DOCENTE NA EDUCAÇÃO DO CAMPO
}

\author{
Wiama de Jesus Freitas Lopes ${ }^{1}$ \\ UFCG \\ Luiz Bezerra Neto ${ }^{2}$ \\ UFSCar
}

\section{RESUMO}

Este texto é parte da pesquisa da tese intitulada "O Desenvolvimento Profissional da Docência em Escolas Multisseriadas Ribeirinhas na Ilha do Marajó-PA" que objetivou analisar o processo de constituição da profissionalidade docente na educação do campo em comunidades ribeirinhas, na Ilha de Marajó PA, mais particularmente no Município de Breves. Teve como problema de pesquisa a questão: "De que modo se constitui a profissionalidade docente em turmas multisseriadas na educação do campo?" Isto, sob a perspectiva de questões educativas estruturais que estão balizando a caracterização dos trabalhos, perfis e posturas de intervenção didática de educadores no processo de escolarização de seus discentes em prol das dinâmicas de formação humana e da qualidade de vida no campo.

Palavras-chave: Profissionalidade docente no campo. Educação do Campo. Multissérie.

\section{THE EDUCATION MULTISSERIATE FORWARD TO TEACHING PROFESSIONALISM IN RURAL EDUCATION}

\begin{abstract}
This text is part of the research thesis entitled "The Professional Development of Teaching in Schools Multiseriated River on Marajó Island-PA" that aimed to analyze the process of formation of the teaching profession in the rural education in riverside communities on the island of Marajó PA more particularly in the municipality of Breves. Research problem was to the question: "How does the teaching profession is in multigrade classes in the rural education?" This, from the perspective of educational issues that are underlain structural characterization of jobs, profiles and postures of didactic intervention educators in the schooling process of their students in favor of the dynamics of human development and quality of life in the countryside.
\end{abstract}

Keywords: Teaching professionalism in countryside; rural education; Multigrade.

Discutir o problema da profissionalidade docente consiste numa tentativa de compreender a organização do trabalho do professor e o seu desenvolvimento tanto na sala de aula quanto na comunidade em que este se insere. Esta problemática ganha maior proporção à medida em que o trabalho se desenvolve com as classes multisseriadas no campo. Para isto, deve ser considerado alem das condições de trabalho e renda, as condições de moradia e as relações que se estabelecem na comunidade. 
A multisseriação ou multissérie pode ser caracterizada pela reunião em um mesmo ambiente pedagógico e, sobretudo, em uma mesma sala de aula de diferentes séries ou anos letivos sob a responsabilidade docente de um único educador. O que pode chegar geralmente ao agrupamento discente de até cinco grupos diferentes de alunos que em quantidades e faixa-etárias diversas que poder ir da educação infantil à $4^{\underline{a}}$ série ou $5^{\underline{0}}$ ano. Este único educador incumbido por uma determinada turma multisseriada assume múltiplas funções tais quais a de faxineiro, a de professor, a de merendeiro, a de coordenador pedagógico (para a interação junto aos pais, pesponsáveis e comunidade escolar), a de secretário da unidade educacional em que exerce sua unidocência, a de cuidador (quando vem a ser o caso) e a de executor financeiro do PDDE, por vezes; além da tarefa de alfabetizador e docente de um grupo altamente heterogêneo em seus estágios cognitivos/formativos. E,

Apesar do seu alto índice de fracasso escolar, a multissérie ainda é um "apêndice" do paradigma da escola seriada urbanocêntrica, pois não possui um tratamento diferenciado. Trata-se de uma realidade ignorada, inclusive nas estatísticas sobre educação no país (HAGE; ALMEIDA, 2006, p. 14).

Outra realidade que quase não aparece aos olhos da sociedade é o fato de que é comum que os professores, por vezes, residam nas instalações físicas da própria unidade escolar em que trabalham, ou em quartos de casas cedidas pela comunidade, juntamente com as famílias cedentes. No entanto, o problema mais recorrente na multissérie é fato de o professor ter que lidar, no mesmo ambiente pedagógico de sala de aula e, ao mesmo tempo, com o fato de ensinar — em dias específicos da semana —, quando em matemática, por exemplo, conjunto unitário para um grupo de alunos do começo das séries iniciais e, concomitantemente, multiplicação com dois algarismos para os alunos que finalizam o segmento das séries iniciais. O mesmo acontece com as unidades temáticas do conteúdo programático de língua portuguesa - e das demais disciplinas - com níveis de complexidade e de destinação a diferentes séries, todos os dias em uma sala de aula multisseriada, praticamente sem estrutura de espaço, de mobiliário escolar, de equipamentos e recursos pedagógicos ou até mesmo sem o apoio de livros didáticos potencializadores de orientação para a dinâmica de trabalho unidocente.

Embora os professores da multissérie tenham desenvolvido também a estratégia de ensino cooperativo, onde alunos mais avançados auxiliam alunos em desenvolvimento em um determinado processo de apropriação de uma temática do conhecimento escolar, tais docentes da multissérie, queixam-se em demasia, com o ritmo truncado em que ocorre a aprendizagem, dada a heterogeneidade dos alunos da multissérie.

Se não há consenso entre os docentes da multissérie, com relação ao fato de saber se o aluno realmente é prejudicado no quanto se aprende, há um certo reconhecimento de que a heterogeneidade pode ser algo produtivo e a ser contado a favor do trabalho pedagógico em sala de aula, mas no geral, reclamam das condições em que têm de lidar na escola com educandos da faixa-etária dos 12 aos 14 anos e, concomitantemente com crianças de 6 a 8 anos em processos heterogêneos distanciados entre si pelos estágios de formação humana em que atravessam.

Tais circunstâncias são quase sempre imperativas para discussão ou problematização em sala de aula, o que nem sempre é apropriado ou até mesmo aproveitado de modo significativo para um ou outro grupo nas faixas-etárias acima mencionadas. Nesse sentido, muitos professores reclamam que encontram dificuldades para responder ou trabalhar questões ligadas às doenças sexualmente transmissíveis ou 
métodos contraceptivos para o grupo de finalização das séries iniciais ${ }^{3}$ com a turma também composta por crianças de 6 a 9 anos de idade, cuja discussão pode ser ainda precoce e o entendimento das questões não se dá de forma adequada. Outra preocupação que se dá é com relação aos pais que muitas vezes entendem ser esta discussão inadequada para uma criança que pode não estar preparada para ela.

Outro problema basilar da multissérie está na proteção do tempo de aula para cada grupo de alunos, que em príncípio correspondem a uma determinada série. Questão da qual comumente se queixam os docentes da turma multisseriada. Ximenes-Rocha apresentando uma pesquisa que discute uma questão nesta natureza, destaca

Em uma sala de aula da professora Ceci, observou-se que a ausência de divisão de tempo para cada turma fez com que ela só pudesse dar atenção aos alunos de $2^{\mathrm{a}}$ série cerca de uma hora depois que a aula havia começado. Foi alertada pelo apelo de uma aluna [...]. Naquele dia, [...] a professora dedicou $33 \mathrm{~min}$ para a $1^{\mathrm{a}}$ série, $21 \mathrm{~min}$ para a $2^{\mathrm{a}}$ série, $52 \mathrm{~min}$ para a terceira série e fez $21 \mathrm{~min}$ de intervalo. Notou-se situação semelhante nas aulas da professora Iara, nas quais se dedicava mais tempo aos alunos de $1^{\mathrm{a}}$ série (XIMENES-ROCHA, 2012, p. 35).

A autora preocupada com esta circunstância, chama a atenção para o "descumprimento" da legislação em vigor ao continuar afirmando que

a LDB 9.394/96 estabelece, no Capítulo II da Educação Básica, Seção I das Disposições Gerais, Art. 23, parágrafo $2^{\circ}$, que o calendário escolar deverá adequar-se às peculiaridades locais, inclusive climáticas e econômicas, a critério do respectivo sistema de ensino, sem com isso reduzir o número de horas letivas previsto nesta Lei; no Art. 24, no item I, que a carga horária mínima anual será de oitocentas horas, distribuídas por um mínimo de duzentos dias de efetivo trabalho escolar, excluindo o tempo reservado aos exames finais, quando houver; na seção III, que trata do Ensino Fundamental em seu Art. 34, que a jornada escolar no Ensino Fundamental incluirá pelo menos quatro horas de trabalho efetivo em sala de aula, sendo progressivamente ampliado para o período de permanência na escola" (XIMENESROCHA, 2012, p. 35 - Grifos no original).

Como fator de agravamento deste contexto é comum se encontrar turmas multisseriadas que tenham cinco séries ou anos letivos em uma mesma sala de aula com um total de até 25 alunos. Tais alunos, nas mais diferentes composições quantitativas, são agrupados como, por exemplo: com 5 alunos da primeira série, 9 da segunda série, 4 da terceira série, 6 da quarta série e um ou dois alunos da educação infantil.

Tendo em vista a composição das salas nas condições acima mencionadas, a dinâmica de trabalho balizada pelo fracionamento do tempo de sala de aula também pode ser ser facilmente constatada pelas várias pesquisas disponíveis e principalmente pela que empreendeu este artigo e de modo quase unânime dentre os sujeitos entrevistados. Entre tais sujeitos há professores com compreensões e posturas contrárias ao ordenamento estratégico da multissérie, sobretudo em função da proteção do tempo de aula. O que pode ser ilustrado pelo excerto abaixo:

Porque... o aluno sem ser de multissérie... é normal... ele tem quatro horas por dia, quatro horas por dia para aprender. Já na multissérie é diferente! Ele não tem toda essa carga horária porque eu tenho quatro séries ao mesmo tempo em quatro... em quatro horas... Eu tenho quatro 
séries, até mais... Por exemplo: uma para uma turma, uma hora para outra, uma hora para outra... Isso se resume em que? Por exemplo: Em um ano eu tenho 200 horas... Ou seja, 200 dias, resumindo tudo isso aí, vai dar 100 dias letivos. Há um trabalho com dano... eu trabalho só 100 dias letivos quanto à carga horária daquela criança que vai ser de 100 dias letivos. Eu tenho no meu ponto de vista, isso! Vai ser 100 dias letivos! Ou seja... e os outros 100? Vai faltar? Para a criança aprender... Ah, professor, mas porque o senhor não trabalha tudo isso?! Mas não dá! Se eu tenho de quarta série ainda... eu tenho que atender a esse aqui e esse aqui fica parado. Mesmo que tenha o aluno colaborador não dá para contar para tudo. Não pode! O conteúdo está aqui, aqui, aqui... Vou para outra e essa aqui, a de quarta série, vai perder tempo. Mais outra hora que eu vou... Teria que lecionar para eles e daí eu pego outro e assim vai. Não dá certo. Com a multissérie não dá certo! É um problema muito grande! (Professor Lua, em entrevista. Distrito São Miguel-Breves PA. 12/06/2011).

As considerações acerca da dinâmica de trabalho caracterizada pelo fracionamento do tempo de efetivo atendimento aos agrupamentos de alunos em sala de aula continuam a serem registradas recorrentemente entre os sujeitos desta pesquisa, tal qual:

O problema é a questão das idades... Até porque quando você tem uma turma... Eu já trabalhei logo no primeiro ano com turma de primeira à quarta séries e eu tinha uns cinco níveis ali dentro, entendeu? Os cinco níveis de aprendizagem com os meus alunos. Então dificulta muito o nosso trabalho. Não tem nada comparado com uma turma de multissérie. $\mathrm{Na}$ cidade, por exemplo, uma turma de primeiro ano que ela é... digamos assim... selecionada por idade, por nível de aprendizagem... então, o nosso trabalho é muito árduo. Você pode até me dizer: mas não professora numa turma só de primeira série também se tem uma heterogeneidade ali! Quatro diferentes níveis ali dentro de uma só série. Mas veja! Na multissérie essa heterogeneidade se amplifica! Ninguém imagina o quanto! Ninguém tem noção do que a gente enfrenta! Do que é ser... do que é enfrentar uma turma de multissérie! (Professora Pink, em entrevista. Distrito de São Miguel-Breves PA. 12/06/2011).

Há algumas variáveis passíveis de análises nesta questão. No entanto, três são fundantes: a primeira trata-se da questão que a multissérie não é trabalhada no campo a partir de uma concepção de educação integrada ao campo, ou como querem os movimentos sociais, a educação do campo. A segunda se delineia pelo fato de que a heterogeneidade da multissérie revela de modo bastante amplificado a distorção idade/série. Neste sentido, há um fato de que em uma mesma sala multisseriada pode ser encontrado adolescentes de 14 anos com vida sexualmente ativa, com hábitos de bebida alcoolica, que frequentam festas comunitárias nas circunvizinhanças de outros Bairros, Centros, Cidades, Praias e/ou Rios, trabalham marcadamente em regimes de prolongadas jornadas de vendedores ambulantes, oficinas (das mais variadas), extrativismo... e em seus processos de escolarização frequentam a mesma turma de crianças de 6 ou 8 anos de idade. A terceira é que todos os educandos, invariavelmente, estão em fases diferentes de aquisição e desenvolvimento de leitura e escrita e com a obrigatoriedade para com conteúdos programáticos outros, pelas séries subsequentes nos grupos dos demais alunos, dentro do primeiro segmento do ensino fundamental. Reunidos para um agrupamento discente em um único ambiente físico e, especialmente, neste caso, em uma sala de aula multisseriada. 
Não é somente o rol de conteúdos que se desdobra e se alterna para com as mesmas disciplinas em seus desdobramentos em séries diferentes que impactam no processo de se lidar com a multissérie, mas enfaticamente a abordagem metodológica que se terá na transposição do conteúdo na condição unidocente junto a tão variado agrupamento discente. Isto, no geral, na condição infraestrutural que se tem de sala de aula da educação do campo.

Se há reclamação com relação ao tempo de trabalho com cada aluno, o mesmo acontece com a organização do trabalho pedagógico que é marcadamente uma variável também a ser considerada nesta questão, haja vista o excerto abaixo:

Sem contar que o planejamento da SEMED muitas vezes não colabora com a gente. Porque se eu tenho um assunto para trabalhar... no caso, se eu for trabalhar adição com a segunda série, na primeira unidade, não... eu vou trabalhar os números com a segunda série na primeira unidade, na terceira série eu já vou trabalhar adição e para a quarta série já vem multiplicação... subtração... Eles não fazem assim um planejamento que dê para se trabalhar o mesmo conteúdo, ao mesmo tempo, com todas as séries. Variando o grau de complexidade. Não se trabalha quase nada nisso. Claro que a gente vai ter que se aprofundar mais num e menos em outro grupo seriado de alunos na multissérie. No meu caso, eu tenho que fazer um replanejamento do que a SEMED me dá... eu tenho que replanejar para que eu não fique... não fique muito repetitivo. Porque se eu for trabalhar hoje números com a segunda série, adição com terceira e subtração com a quarta, no outro dia em que eu for trabalhar adição com a segunda, a primeira já fez aquilo e a quarta também já. Então, isso fica meio repetitivo e a gente acaba se prendendo no conteúdo e geralmente, no ano inteiro, não dá para trabalhar todos os conteúdos que eles colocam para gente trabalhar. Porque tem que estar todo o tempo com o conjunto de todos os conteúdos de todas as séries em vista! E olha que a gente sempre sabe que tem de fazer uma revisão de vez em quando... Mas aí, nesse planejamento, é uma coisa que eu acredito que deixa a desejar. Porque daria para se trabalhar apenas um conteúdo com todo mundo e com seus níveis de complexidade com todas as séries e isso não acontece (Professora Vieira, em entrevista. Distrito de São Miguel dos MacacosBreves PA. 13/06/2011).

Neste contexto há um dado a ser aqui considerado que é o fato de que - a expressão docente no protagonismo da atuação profissional - assume uma corporificação marcada por um elemento que sempre estaria, de qualquer modo, cravado nas configurações profissionais da docência; mas que aqui, ou pela proporção de não concursados no quadro docente da multissérie ou pela fragilidade da coletividade enquanto um grupo coeso, o aspecto pessoal da necessidade de ocupação assume um lugar estrategiamente central na vivência do vínculo docente e assim deflagra questões como:

Nós trabalhamos com a multissérie porque realmente é preciso! Prefeito nenhum vai contratar 4 professores para uma escola lá da ribeira longe que tem 29 alunos. Destes, com quatro da quarta, nove da terceira, onze da primeira e cinco da segunda. É um mal necessário essa multissérie! Quisera que todas nós pudéssemos trabalhar com uma só série em cada horário. Porque nós com certeza iríamos fazer um trabalho bem melhor; ajudar melhor aos alunos. Então, a gente trabalha assim... eu trabalho com multissérie porque eu não tenho outra opção (Professora Mirí, em entrevista. Distrito Antonio Lemos-Breves PA. 11/06/2011). 
Uma diversidade de variáveis toma a leitura do cenário. Como se o pouco envolvimento docente nas políticas locais de configuração das práticas educativas na multissérie não fosse um fardo para as garantias de trabalho a lógica do custo benefício se torna não só o fundamento, mas por vezes a matriz da lógica de leitura do cenário.

As escolas do campo geralmente possuem uma única turma por turno letivo. $\mathrm{O}$ que faz da sala de aula multisseriada ser caracterizada como a própria escola da multisseriação, no campo. Outro fator que os sujeitos de parte da pesquisa que gerou este artigo apontam como desfavorável à multissérie é o fato da gestão que o sistema do ensino fundamental público de Breves PA fez deixando coexistir séries e anos letivos a partir da implementação do ensino fundamental de 9 anos. A existência de crianças de seis anos, em uma sala de aula multisseriada, é desvantajosa, segundo os educadores do campo. Eles apontam que ao passo que precisam escolarizar uma criança de quarta série, ao mesmo tempo precisam trabalhar com crianças de 6 e 7 anos em um segundo conjunto que, a rigor, não possuem as mesmas habilidades entre si. Segundo consenso dentre os sujeitos desta pesquisa há crianças de seis anos que não estão com a fala realmente definida e que possuem muitas dificuldades com os pratos e as colheres ao passo que crianças de 7 anos possuem um pouco mais de segurança em relação a tais quesitos. Segundo os educadores da amostra deste trabalho, esta é uma questão que pesa no transcorrer de suas obrigações no trabalho pedagógico para com a escolarização de um grupo de até 25 alunos com uma variação de até 8 crianças de 6 e 7 anos em meio ao coletivo de alunos a serem escolarizados das séries iniciais do ensino fundamental.

Os educadores do campo apresentando os problemas estruturais da multissérie, ao que concerne esta questão, mencionam que antes da implementação do ensino fundamental de 9 anos trabalhavam com a "alfabetização na perspectiva da educação infantill", segundo eles. E um dos fatores determinantes do ensino fundamental de 9 anos foi transpor a alfabetização para o ensino fundamental. Só que isto, na educação do campo, gerou um impasse ainda mais potencial que na seriação urbana. Pois, sobretudo, a falta de estrutura das escolas do campo e a ineficiência de um projeto de formação continuada aos educadores do campo agravam em intensidade e em maiores implicações procedimentais a ação educativa na multissérie em relação a esta necessária mediação didática, junto a um coletivo discente em que há crianças — em nível de habilidades já desenvolvidas "vindas do lar", como definem os educadores.

Faz-se necessário destacar que o Plano Nacional de Educação (PNE), aprovado pela Lei $n^{\circ}$ 10.172/2001, em consonância com a Lei de Diretrizes e Bases da Educação Nacional, a 9394/96, traz em suas diretrizes a implantação progressiva do Ensino Fundamental de 9 anos, pela inclusão das crianças de seis anos de idade. Neste sentido as Orientações para o Ensino Fundamental de nove anos, do Ministério da Educação, ressaltam que a criança de 6 anos em sua acolhida no processo de escolarização precisa continuar sistematicamente

descobrindo e, progressivamente, aprendendo a usar as múltiplas linguagens: gestual, corporal, plástica, oral, escrita, musical e, sobretudo, aquela que lhe é mais peculiar e específica, a linguagem do faz de conta, ou seja, do brincar. Sua relação com o outro, consigo mesma e com diferentes objetos da natureza e da cultura que a circundam é mediada por essas formas de expressão e comunicação (BRASIL/MEC/SEB, 2004, p. 19).

Para tanto destaca que, 
as estratégias pedagógicas devem evitar a monotonia, o exagero de atividades "acadêmicas" ou de disciplinamento estéril. [...] Por isso, desde a organização do espaço, móveis, acesso a brinquedos e materiais, aos locais como banheiros, cantinas e pátios, até a divisão do tempo e do calendário anual de atividades, passando pelas relações e ações conjuntas com as famílias e os responsáveis, o papel dos educadores é legitimar os compromissos assumidos por meio das propostas pedagógicas (BRASIL/MEC/SEB, 2004, p. 15).

O mesmo documento de Orientações destaca que neste âmbito "promover a formação continuada e coletiva é uma atitude gerencial indispensável para o desenvolvimento de um trabalho pedagógico qualitativo" (BRASIL/MEC/SEB, 2004, p. 25) ao que concerne ao trabalho com crianças de 6 anos no ensino fundamental. No entanto, mesmo sendo altamente necessária esta formação em caráter continuado aos professores da multissérie ribeirinha de Breves esta medida administrativa não resultaria na superação em definitivo das implicações pedagógicas na multissérie para com ação educativa em um coletivo com crianças de seis anos. Isto para além do fato de que "o ingresso dessas crianças no ensino fundamental não se pode constituir numa medida meramente administrativa" (MEC/SEB, 2007, p. 6).

Diante dos registros de insatistafação de grande parcela dos professores para com o fracionamento do tempo de atendimento aos alunos é notório que a gestão da multissérie vem descumprindo as normativas legais quanto ao tempo devido de aula no processo de escolarização dos sujeitos do campo. Isto implica no fato de se pensar uma alternativa de reordenamento curricular junto à multissérie que passa tanto pela ampliação da jornada escolar para o atendimento em tempo integral dos educandos do campo, quanto por outras possibilidades e fundamentos curriculares de agrupamento discente nas séries iniciais.

Diante destas dificuldades apresentadas sobre o trabalho na multisseriação é fundamental compreendamos as implicações que este modelo de escola, sobretudo a escola unidocente, em que o professor é merendeiro, secretário de escola, diretor, faxineiro, conselheiro de pais e até profesor, traz tanto para a sua formação, quanto para o desenvolvimento da sua profissão, ou como apontamos no início do artigo, para a sua profissionalidade.

Para que se possa ser definida a expressão profissionalidade, no âmbito do trabalho docente, se deve passar a priori pela conceituação de profissão. Para tanto, na acepção de profissão podemos recorrer ao ideário de organização coletiva que uma profissão requer; bem como a validação e a implementação do trabalho em equipe e os consideráveis níveis de autosatisfação que geralmente incita a consolidação de uma determinada profissão, sobretudo as liberais. Cabe aqui ressaltar que segundo Gimeno Sacristán (1995) são as práticas concorrentes, que constituem atividades fora do sistema escolar, que em larga medida vêm determinando quais competências docentes são menos ou mais necessárias dentro da profissão docente e, portanto, com influência direta sobre a função dos professores em suas caracterizações profissionais. Tais práticas concorrentes podem ser traduzidas pelo: desenvolvimento curricular regulado pela administração educativa, os materiais didáticos oriundos destas, os mecanismos de supervisão das escolas e o controle dos professores, assim como a política educativa. Portanto, olhando a partir de todos esses descritores, pode-se dizer que a docência é por si uma profissão?

De antemão deve-se considerar que a profissão docente lida com o trabalho educativo e, por sua vez, 
O trabalho educativo é o ato de produzir, direta e intencionalmente, em cada indivíduo singular, a humanidade que é produzida histórica e coletivamente pelo conjunto dos homens [...] para produzir materialmente o homem precisa antecipar em idéias e objetivos da ação que significa que ele representa mentalmente os objetivos reais. Essa representação inclui o aspecto das propriedades do mundo real (ciência), de valorização (ética) e de simbolização (arte). Tais aspectos, na medida em que são objetos de preocupação explícita e direta, abrem a perspectiva de uma outra categoria de produção que pode ser traduzida pela rubrica "trabalho não-material". Trata-se aqui da produção de idéias, conceitos, valores, símbolos, hábitos. Numa palavra, trata-se da produção do saber, seja do saber sobre a natureza, seja do saber sobre a cultura, isto é, o conjunto da produção humana. Obviamente, a educação situa-se nessa categoria de trabalho não-material (SAVIANI, 2011, p. 6).

É neste contexto diferenciado de uma produção não material que deve se dar a discussão sobre a profissionalidade docente. Discussão esta que deve ser permeada pela sociologia das profissões ao considerar o trabalho e por conseguinte, a profissão docente em suas singularidades. Por outro lado, temos observado que alguns estudos acerca do trabalho do professor junto às organizações sindicais de docentes vem construindo uma concepção que leva a entender, pelo menos ao nível dos discursos que há um processo de proletarização do professor.

Sem dúvida a docência enquanto profissão está em uma área de litígio semântico. Segundo Careaga (2007, p. 3), o termo profissão possui alguns convencionais descritores enquanto categoria de análise. Para ela, a profissão goza socialmente de um determinado prestígio social. Este, por sua vez, confere às profissões certa reputação tendo em vista a segurança que é peculiar nas representações sociais de profissão. As profissões são marcadas por um determinado código de ética, como destaca Careaga (2007) e por consensos mais ou menos definidos quanto à função social da atividade profissional que se presta. Estes dois descritores, que na sociologia das profissões colaboram para definir a semântica de profissão, não são exatamente categorias que deixam o ofício docente em posição cômoda para caracterização.

Outro fator relevante na discussão sobre os aspectos da profissionaidade docente é o que diz respeito à inexistência de controle sobre a própria remuneração, bem como a carência de mecanismos de responsabilização sobre os próprios atos profissionais, que também interferem de modo negativo para que definamos enquanto profissão o status desta ocupação. Estes descritores destacados fazem parte da conceituação de profissão. Os estudos acerca da sociologia das profissões também reputam como descritores de profissionalidade o corpo de habilidades básicas e comuns para o exercício da função, bem como uma matriz de conhecimentos definida e partilhada pela comunidade científica na qual o profissional fora formado. Um prolongado período de formação e de acompanhamento técnico por ocasião do início das atividades profissionais também são pressupostos de conceituação da categoria profissão. Cada um destes últimos descritores significa para a profissão docente marcos de caracterização que instabilizam o entendimento, pelo menos o convencional, do que possa vir a ser a docência enquanto profissão. Todavia, embora que diferenciadamente, a docência é em si uma profissão.

Aqui, independentemente da discussão sociológica sobre as profissões é preciso lembrar que os profissionais do ensino - os professores - dependem do seu trabalho remunerado para sobreviver e se reproduzir como tal. Cada vez mais, o ser professor vem 
recusando a "pecha" de sacerdócio e buscando mecanismos de organização profissional, com vistas à sua manutenção como tal.

Portanto, como fatores referenciais de constituição da profissionalidade docente - em especial a da docência no campo —, neste caso, pode-se afirmar que esta profissionalidade se caracteriza pela busca sistemática e politicamente duradoura de condições materiais de trabalho nas escolas do campo e de implementação de um outro modelo de organização sócio-comunitária e até mesmo de sociedade. Tendo em vista uma matriz científico-tecnológica pautada por dinâmicas produtivas socialmente justas, economicamente viáveis e ecologicamente sustentáveis. E, para tanto, é caro para as bases de formação da profissionalidade docente no campo a construção de um modelo de organização social pautado pela segurança alimentar e de qualidade de vida no campo. Isto, com a compreensão de que a função social basilar da escola é a emancipação humana, tendo o processo de organização coletiva e de territorialização como pressupostos de ordenamento também do trabalho na ação educativa.

Para a continuidade desta discussão é caro considerar que, em princípio, no entendimento da acepção de trabalho na ação educativa está a concepção do termo trabalho. Antes de tudo, na ação educativa das escolas do campo, o trabalho é o elemento que estabelece dialeticamente a relação entre a teoria e a prática. Relação esta pela qual endogenamente o ato do planejamento orienta a ação educativa e esta, por sua vez, implica tanto na lapidação e na consistência do planejamento da ação educativa quanto no projeto de trabalho pedagógico que a educação empreende no campo. Isto aliado a um sentido histórico de buscar e empreender uma dimensão ético-política de se produzir, preservar e promover as bases materiais da vida material dos povos do e no campo.

Neste sentido o trabalho é um elemento que se realiza como projeto, via não somente um sentido, mas sobretudo, como e por meio de uma ação coletiva. Assim, ao passo que o trabalho transforma a natureza em função de um projeto coletivo daqueles que o empreendem, pelo próprio trabalho, os povos do campo produzem a si mesmo por intermédio do nível de consciência e da ação vinculada aos processos produtivos de intervenção sobre a natureza. Uma intervenção sobre a natureza tanto a de si quanto aquela de sua configuração geográfica em seu espaço/tempo. Dessa forma, como "em sua lógica de produção o homem deve libertar o trabalho do sentido e das práticas de aprisionamento do capital" (FREITAS, 2010, 160). Para tanto, as ações de intervenção sobre a natureza e as relações sociais de produção vão desde a educação para e no trabalho socialmente útil até à implementação de condições objetivas de superação da perspectiva do assalariamento no campo e na cidade.

Isto implica em aprendizagens que demandem formação teórico-metodológica sólida, fomentada com disciplina de organização e para com a visão de mundo na qual se busque um outro modelo de sociedade, de relações de produção e de conhecimento que delineiem com humanização as condições materiais da vida no e do campo. Eis os desafios da formação e das práticas educativas da educação do campo, sobretudo na base da profissionalidade docente. E, para tanto, continuar na multissérie, de acordo com a maioria dos professores se faz contraproducente para o aporte deste perfil de formação profissional do educador do e no campo.

Assim sendo, é urgente que se pense uma alternativa de ordenamento curricular para a sistemática de trabalho pedagógico na educação propedêutica do campo que não seja, definitivamente, a metodologia do Programa Escola Ativa ${ }^{4}$. Pois esta proposta de orientação curricular aconteceu e acontece de modo apartado das especificidades da vida dos povos do campo. Haja vista que, segundo o verbete Escola Ativa (D'AGOSTINI; SANTOS JÚNIOR; TAFFAREL, 2012, p. 315) do Dicionário sobre Educação do Campo 
(CALDART et al., 2012), este programa traz consigo as seguintes características: a) a negação do conhecimento científico como base imprescindível para a consciente explicação e ação na realidade e, em seu lugar, coloca-se o imediatismo e o subjetivismo; b) dos consensos estabelecidos, exclusão, coerção e criminalização dos movimentos de luta social e das organizações sindicais da classe trabalhadora; c) da avaliação controlada ideologicamente; d) da marginalização da referência teórica de base materialista histórica e dialética nos currículos; e) do silenciamento das leis que regem o modo de produção capitalista, da luta de classes e do Estado burguês; f) da ausência de referência ao projeto histórico de superação da sociedade de classes, o projeto histórico socialista. Reafirmando o Projeto Escola Ativa "estes aspectos, em maior ou menor grau, que se expressam nas políticas públicas educacionais, dado que estas são o resultado da correlação de forças entre as classes" (TAFFAREL et al., 2012a).

Como estratégias de superação das dificuldades encontradas na multissérie ou até mesmo o fim de sua existência na organização curricular na educação do campo, inicialmente, tem-se que pensar em uma estratégia de ordenamento do currículo com configuração de seus coletivos docentes, técnico-pedagógicos, comunitários, militantes e demais envolvidos no processo de escolarização no campo. É preciso que se pense em uma estrutura de ensino e aprendizagem a partir de da organização do saber que não se reduza a projetos de vida, mas que tenha por base a organização e as dinâmicas de abertura, engajamento, consciência e preparação para este (re)dimensionamento, antes de tudo, da pedagogia necessária ao campo que não exclua de modo algum o conhecimento escolar historicamente acumulado.

Isto posto, como aporte possível, o princípio desta mobilização educativa pode ter como alternativa inicial a proposta da pedagogia histórico-crítica como concepção teóricometodológica de trabalho nos processos de escolarização nas séries iniciais da Educação do Campo. Além de que esta mobilização também conta para o mesmo intuito, com os ciclos de formação como possibilidades exequíveis para organização sistêmica do quadro curricular na Educação do Campo.

Uma possibilidade de superação da multissérie pode se dá através do trabalho em torno dos ciclos de formação, que podem mais precisamente ser utilizados, considerando os estudos de Freitas (2002), Arroyo (1999), Franco (2001) e Krug (2001). Obviamente lidos em suas possibilidades para com a ação educativa de superação das condições materiais de trabalho junto às turmas multisseriadas ribeirinhas no contexto da Educação do Campo. E, no aporte da questão da pedagogia histórico-crítica, esta problematização seria referenciada mais especificamente pela produção de Dermeval Saviani (2011) e por Marsiglia (2011) em prol da superação dos gargalos estruturais que existem na operacionalização da gestão e dos procedimentos docentes teórico-metodológicos junto à multissérie.

Neste sentido, não se propõe aqui uma refutação total e imediata à multissérie. É das estruturas dadas de operacionalização do trabalho docente em sua constituição da profissionalidade que nascerá uma estratégia superadora das dificuldades teóricometodológicas existentes na unidocência desta multisseriação. E, portanto, esta estratégia pode vir inicialmente experimentada não necessariamente pela conciliação entre os Ciclos de Formação e a Pedagogia Histórico-Crítica, mas de uma síntese ou de uma consubstanciação teórico-metodológica vindas a partir das experiências com ambas as propostas e, por conseguinte, levando em consideração, especialmente, as peculiaridades de ordenamento jurídico-educacional da Educação do Campo. Pois vale ressaltar que a Lei n 0 9.394, de 20 de dezembro de 1996, em seu Art. 23, considera que "a educação básica poderá organizar-se em séries anuais, períodos semestrais, ciclos, alternância regular de 
períodos de estudos, grupos não seriados, com base na idade, na competência e em outros critérios, ou por forma diversa de organização, sempre que o interesse do processo de aprendizagem assim o recomendar".

Definitivamente, neste sentido, a discussão não passa simplesmente pela suplantação da multissérie com a proposta de implementação de ciclos. Já no primeiro ciclo estarão juntas crianças de 6 a 8 anos de idade. Haja vista que no que tange à alfabetização, uma criança de 8 anos já está, geralmente, no nível alfabético, sendo que a criança de 6 anos, por sua vez, é comum que esteja iniciando de modo mais sistemático o nível pré-silábico. Crianças em diferentes níveis de aprendizagens, dentro de um mesmo ciclo de formação e - em um mesmo agrupamento discente - em contato necessário com conteúdos diferentes. Portanto, a alternativa da multissérie não se consubstancia com a suplantação da forma de organização do trabalho pedagógico multisseriado pela implementação de ciclos, simplesmente. $\mathrm{O}$ trabalho com ciclos mesmo lidando com dificuldades resultantes das orientações de crianças em níveis e exigências letivas diferentes é menos intenso e complexo quando observado o cruzamento do conjunto dos conteúdos programáticos por série com outro conjunto correspondente de competências e habilidades. Essa questão obviamente existe e se repete no trabalho com os ciclos, contudo, de modo mais "enxuto" e objetivado.

\section{Considerações finais}

A profissionalidade docente, na prática, não deve se dar no ativismo ou na cotidianidade da ação pedagógica por si; deslocada de coletivos orgânicos ou desvinculada da teoria como fundamento basilar de orientação da própria prática educativa. Isto porque é a práxis o vetor de intervenção nas estruturas dadas e historicamente situadas o elemento fundante da autonomia e responsabilização da ação educativa. E, aí, se concentra um núcleo estruturante da profissionalidade docente. Assim, se tornam pululantes as possibilidades de constituição da profissionalidade docente na Educação do Campo ao passo que são vitais uma melhor organização do trabalho pedagógico da Educação no Campo como respostas aos anseios docentes relativos à multissérie.

Afirmar a profissionalidade na Educação do Campo é uma forma institucionalizada de profissionalizar o ensino nas escolas do campo. Isso implica inicialmente em qualificar ainda mais e legitimar o engajamento docente nos rumos e decisões de (re)estruturação curricular do processo de escolarização nas escolas do campo. Cuja lógica do custo-benefício não fosse mais impositiva e paradigmática. Visualizando, por exemplo, as possibilidades oriundas dos sistemas de complexos e/ou dos Ciclos de Formação, trabalhados teórico-metodologicamente pela Pedagogia Histórico-Crítica; buscando assim uma profícua formação humana e escolarização no campo pela organização do trabalho pedagógico a partir das tensões, contradições e mudanças do processo de uso, ocupação e conservação da terra e de modo sustentável, tendo em vista o aprendizado constante e permanente dos povos do campo trabalhado, envidando cidadania, organização social e sistemas referencializados socialmente de relações sociais de produção.

\section{Referências}

ARROYO, Miguel. Ofício de mestre. Imagens e auto-imagens. Petrópolis: Vozes, 2009.

BRASIL. Ministério da Educação. Secretaria de Educação Básica. Ensino Fundamental de 9 anos: orientações para a inclusão da criança de 6 anos de idade. 2. ed. Brasília, 2007. 
Ministério da Educação. Referências para uma política nacional de educação do campo: caderno de subsídios. Brasília, 2004.

Ministério da Educação. Secretaria de Educação Básica. Ensino Fundamental de Nove Anos - Orientações Gerais. Brasília, 2004.

Conselho Nacional de Educação. Câmara de Educação Básica. Resolução CNE/CEB no 1, de 3 de abril de 2002. Institui Diretrizes Operacionais para a Educação Básica nas Escolas do Campo. Diário Oficial da União, Brasília, v. 67, Sessão 1, p. 32, 9 abr. 2002. Disponível em: portal.mec.gov.br/cne/arquivos/pdf/CEB012002.pdf Acesso em: 31 nov. 2011.

Ministério da Educação. Diretrizes Operacionais para a Educação Básica das Escolas do Campo. CNE/MEC, Brasília, 2002.

Lei n. 9.394, de 20 de dezembro de 1996. Estabelece as diretrizes e bases da Educação Nacional. Diário Oficial da União, Brasília, v. 134, n. 248, p. 27833-41, 1996.

CALDART, Roseli Salete; PEREIRA, Isabel Brasil; ALENTEJANO, Paulo; FRIGOTTO, Gaudêncio (Orgs.). Dicionário da Educação do Campo. Rio de Janeiro, São Paulo: Escola Politécnica de Saúde Joaquim Venâncio, Expressão Popular, 2012.

CAREAGA, Adriana Ramirez. El desafio de ser docente. Montevidéu: Universidad de la República, 2007. Disponível em: http://www.medfamco.fmed.edu.uy/ Archivos/pregrado/Ciclo_Introductorio/Materiales/Ser_docente.pdf. Acesso em: 31 jul. 2010 .

D'AGOSTINI, A.; TAFFAREL, C. Z.; SANTOS JÚNIOR, C. de L. Escola Ativa. In: CALDART, R. S. et al. (Orgs.). Dicionário da Educação do Campo. Rio de Janeiro, São Paulo: Escola Politécnica de Saúde Joaquim Venâncio, Expressão Popular, 2012. p.315326.

FRANCO, Creso. A organização da escolaridade em Ciclos: ainda um desafio para os Sistemas de Ensino. In: FRANCO, Creso (Org.). Avaliação, ciclos e promoção na educação. Porto Alegre: Artmed, 2001. p. 35-54.

FREITAS, Luiz Carlos de. A escola única do trabalho: explorando os caminhos de sua construção. Cadernos do ITERRA, Veranópolis, RS, v. 1, n. 15, p. 155-175, set. 2010.

Ciclo ou séries? O que muda quando se altera a forma de organizar os temposespaços da escola? Trabalho produzido para o GT 13 Educação Fundamental. 27 ${ }^{\mathrm{a}}$. Reunião Anual da ANPEd, Caxambu (MG) de 21 a 24 de novembro de 2004.

HAGE, Salomão Antonio Muffarrej; ALMEIDA, Luciane Soares. Movimentos sociais populares do campo e a afirmação do direito à educação: uma questão que envolve saber e poder. In: ENCONTRO DA REDE RURAL, 1. 2006, Niterói. Anais... Niterói- RJ: NEAD, 2006.

KRUG, Andréa. Os ciclos de formação: uma proposta transformadora. Porto Alegre: Mediação, 2001.

SAVIANI, Dermeval. Pedagogia histórico-crítica: primeiras aproximações. 10. ed. São Paulo: Autores Associados, 2011.

TAFFAREL, Celi Nelza Zülke. O sistema de complexos. Salvador, 2012. Texto no prelo.

XIMENES-ROCHA, Solange Helena. A aprendizagem da docência em salas multisseriadas. In. XIMENES-ROCHA, Solange Helena; COLARES, Maria Lília Imbiriba 
Sousa. Formação de professores: pesquisas com ênfase na escola do campo. Curitiba: CRV, 2012. p. 31-43.

\section{Notas}

1 Pedagogo. Mestre em Educação - UFPA e Doutor em Educação pela UFSCar. Membro do GEPERUAZ/UFPA e do Grupo de Estudos e Pesquisas em Ética, Planejamento e Gestão Educacional, da UFCG. Docente da Universidade Federal de Campina Grande - Campus Cajazeiras. E-mail: uiama@uol.com.br

${ }^{2}$ Filósofo. Mestre e Doutor em Educação pela UNICAMP. Professor do Programa de Pós Graduação em Educação - PPGE. Departamento de Educação da UFSCar. Coordenador do Grupo de Estudos e Pesquisas sobre Educação do Campo - GEPEC/UFSCar. E-mail: $\underline{\text { lbezerra@ufscar.br }}$

${ }^{3}$ E nesses grupos é comum encontrar alunos de até 17 anos.

${ }^{4}$ Única proposta para as classes multisseriadas no campo, apresentada pelo governo federal.

Recebido em abril-13

Aprovado em maio-13 